\title{
BMJ Open Impact of reimbursement rates on the length of stay in tertiary public hospitals: a retrospective cohort study in Shenzhen, China
}

Jie Ning, ${ }^{1}$ Lingrui Liu, ${ }^{2}$ Emily Cherlin, ${ }^{2}$ Yarui Peng, ${ }^{1}$ Jingkai Yue (D),${ }^{1}$ Haoling Xiong, ${ }^{1}$ Hongbing Tao ${ }^{1}$

To cite: Ning J, Liu L, Cherlin E, et al. Impact of reimbursement rates on the length of stay in tertiary public hospitals: a retrospective cohort study in Shenzhen, China. BMJ Open 2020;10:e040066. doi:10.1136/ bmjopen-2020-040066

- Prepublication history and additional material for this paper are available online. To view these files, please visit the journal online (http://dx.doi. org/10.1136/bmjopen-2020040066).

Received 18 May 2020 Revised 15 0ctober 2020 Accepted 28 October 2020

D Check for updates

(c) Author(s) (or their employer(s)) 2020. Re-use permitted under CC BY-NC. No commercial re-use. See rights and permissions. Published by BMJ.

${ }^{1}$ Department of Health Administration, School of Medicine and Health Management, Tongji Medical College, Huazhong University of Science and Technology, Wuhan, China

${ }^{2}$ Department of Health Policy and Management, Yale School of Public Health, Global Health Leadership Initiative, Yale University, New Haven, Connecticut, USA

Correspondence to

Mr Jingkai Yue;

yuejingkai1995123@live.com

\section{ABSTRACT}

Objective To examine the association between

reimbursement rates and the length of stay (LOS).

Design A retrospective cohort study.

Setting The study was conducted in Shenzhen, China by using health administrative database from 1 January 2015 to 31 December 2017.

Participants 6583 patients with acute myocardial infarction (AMI), 12395 patients with pneumonia and 10485 patients who received percutaneous coronary intervention ( $\mathrm{PCl}$ ) surgery.

Measures The reimbursement rate was defined as one minus the ratio of out-of-pocket to the total expenditure, multiplied by $100 \%$. The outcome of interest was the LOS. Multilevel negative binomial regression models were constructed to control for patient-level and hospital-level characteristics, and the marginal effect was reported when non-linear terms were available.

Results Each additional unit of the reimbursement rate was associated with an average of an additional increase of 0.019 (95\% Cl, 0.015 to 0.023$), 0.011$ (95\% Cl, 0.009 to 0.014$)$ and $0.013(95 \% \mathrm{Cl}, 0.010$ to 0.016$)$ in the LOS for inpatients with $\mathrm{AMI}$, pneumonia and $\mathrm{PCl}$ surgery, respectively. Adding the interaction term between the reimbursement rate and in-hospital survival, the average marginal effects for the deceased inpatients with AMI and $\mathrm{PCl}$ surgery were $0.044(95 \% \mathrm{Cl}, 0.031$ to 0.058$)$ and 0.034 ( $95 \% \mathrm{Cl}, 0.017$ to 0.051$)$, respectively. However, there was no evidence that higher reimbursement rates prolonged the LOS of the patients who died of pneumonia $(95 \% \mathrm{Cl},-0.013$ to 0.016$)$.

Conclusions The findings indicate that the higher the reimbursement rate, the longer the LOS; and implementing dynamic supervision and improving the service capabilities of primary healthcare providers may be an important strategy for reducing moral hazard in low-income and middle-income countries including China.

\section{INTRODUCTION}

The rapidly developing emerging markets have become increasingly important in low/ middle-income countries (LMICs) ${ }^{1}$; and the share of global medical spending by five major emerging markets, including Brazil, Russia, India, China, South Africa (BRICS) has been
Strengths and limitations of this study

- This study constructed a two-level negative binomial regression model to nest the sampled inpatients (first level) into six or seven hospitals (second level) by taking the clustering of data into account.

- The marginal effect was a way of presenting the difference of the results in probability, which was more informative than incidence rate ratios and relative risks especially when there were interactions in our model.

- Sensitivity analyses were performed by changing disease types to assess the robustness of the findings and to explore the role of disease in this relationship.

- Individual patient-level data from the tertiary public hospital were identified through a robust hospital information system to ensure data quality.

- The study was not able to identify the underlying causal mechanism because data about treatment process were not available.

growing steadily. ${ }^{2-4}$ The same trend is also reflected in the Next Eleven countries, also known as the second-tier group of emerging countries behind the BRICS. ${ }^{5}$ In spite of this, out-of-pocket (OOP) spending in all BRICS countries has risen sharply, from an average purchasing power parity of $\$ 67$ in 1995 to $\$ 276$ in 2012. ${ }^{2}$ The higher OOP expenses might reduce health service utilisation and jeopardise health equity, thus exposing individuals or households in the BRICS to greater risks of catastrophic health expenditure. ${ }^{235-7}$ Despite the diversity of emerging markets, rising OOP expenses is one of the most important obstacles to achieving the universal health coverage (UHC) which is seen as a top priority for improving global health without exposing individuals to financial hardship. ${ }^{389}$ There seems to be a need for greater financial protection for individuals or households in emerging markets, and numerous studies 
have shown that increasing the coverage of health insurance is an efficacious solution. ${ }^{10-14}$ That is why both health insurance coverage and the package of services covered by health insurance plans are expanding in the BRICS countries. ${ }^{7}$

However, there are tough questions to consider. The compelling and overwhelming empirical research and policy experience in developed countries have fully demonstrated that moral hazard is inevitable. ${ }^{15-18}$ The term moral hazard is commonly used to describe the notion that health insurance generosity (often referred to as the OOP payment or effective reimbursement rate) may increase healthcare utilisation. ${ }^{17} 1920$ Healthcare spending increases as insurance coverage expands. ${ }^{17}$ Moral hazard occurs, for example, when an insured person spends an extra day in the hospital or purchases some procedures, even if not necessary. ${ }^{21}$ In traditional economic theory, health economists argue that these increased purchases of healthcare are inefficient because the services they provide are less valuable to consumers than the cost of production ${ }^{1721}$; and excessive reimbursement rates for the entire population can lead to overutilisation of healthcare resources, especially when demand for health services exceeds supply. ${ }^{22}$ Limited reimbursement rates are primarily intended to reduce moral hazard, encourage behaviour that reduces healthcare costs or promotes health. ${ }^{23}{ }^{24}$ Arguably, the phenomenon of moral hazard is a serious impediment to the sustainability of health financing, which is a major challenge for LMICs. ${ }^{25-27}$ Most medium-term economic forecasts predict that growth in BRICS countries is entering a sustainable stage, with a slight slowdown in real gross domestic product growth, meaning that health spending is likely to slow. ${ }^{27}$ Meanwhile, population ageing coupled with the pandemic of chronic non-communicable diseases have become symbolic threats to the sustainability of health financing in LMICs. ${ }^{12529}$

Whereas a number of studies have revealed a correlation between health insurance generosity and utilisation, the research to date has failed to convincingly show how changes in reimbursement rates affect the utilisation of inpatient services in LMICs. In particular, the impact of proportional variations in costs on healthcare utilisation during hospitalisation (often measured as length of stay (LOS)) was rarely studied, but insurance coverage has generally increased inpatient visits and encourages individuals to receive a higher-level care. ${ }^{30}{ }^{31} \mathrm{~A}$ lot of existing literature on reimbursement rates mainly focuses on the utilisation of outpatient service. ${ }^{10} 121422$ Meanwhile, Shen $e t a \hat{l}^{2}$ found that the hospitalisation rate of patients with diabetes and hypertension decreased after the upper limit of reimbursement was raised.

As the largest developing country, China is an important case worth studying. China's social health insurance (SHI) scheme mainly consists of three categories: urban employee basic medical insurance (UEBMI), urban resident basic medical insurance (URBMI) and rural new cooperative medical schemes (NCMS). In
2011, China successfully achieved universal health insurance coverage, achieving remarkable results. ${ }^{33-35}$ China dominates global health spending, followed by India, and will surpass all other emerging markets combined. ${ }^{6}$ ${ }^{36}$ However, the difference in the reimbursement rates of SHI has affected the health service utilisation of the insured, thereby seriously impeding the progress of UHC. $^{30}{ }^{37}$ Although the State Council of China issued opinions on consolidating SHI for urban and rural residents in 2016, there was still a gap between different regional medical insurance schemes, mainly due to different reimbursement standards for medical insurance in different provinces. ${ }^{30} 3839$

In summary, in most of the previous studies, the impact of reimbursement rates on the LOS, especially in the LMICs, has not been distinguished. Therefore, this study set out to shed new light on the association between reimbursement rates and LOS by employing a multilevel negative binomial regression model and fully considering the clustering of data. The standardised electronic records of acute myocardial infarction (AMI), pneumonia and percutaneous coronary intervention (PCI) surgery were used in this study to enable us to better understand the association between inpatients reimbursement rates and the LOS. The interactive effect of inpatient survival on the utilisation of inpatient services was also considered in this study as it was essential to achieve UHC for emerging markets including BRICS countries.

\section{METHODS \\ Data source}

We conducted a retrospective analysis by using standardised administrative electronic health records (EHRs) data. This EHRs system was routinely administered by Shenzhen Public Hospital Management Center, which collected information about over 200 variables including patients' sociodemographic characteristics, diagnosis coded by the International Classification of Disease, Tenth Revision (ICD-10) and procedures coded by the ICD, Ninth Revision (ICD-9), financial data and hospital management indicators. In recent years, EHRs data have become the most authentic, high-quality administrative database in China after a series of data management regulations issued by China's Ministry of Health. ${ }^{40}$ To ensure the uniformity of coding between different hospitals, we invited coding experts of various hospitals to identify a standard for drawing patient data from the EHRs. Besides, the Statistic Annual Report was integrated with EHRs from 2015 to 2017, which contained hospital-level characteristics (such as staff, bed size, medical equipment, medical service, and income and expenditure) for all tertiary-level public hospitals compiled by Shenzhen Public Hospital Administration. The confidential information including name, ID card number, residential address, postal code and insurance number were excluded from the database. 


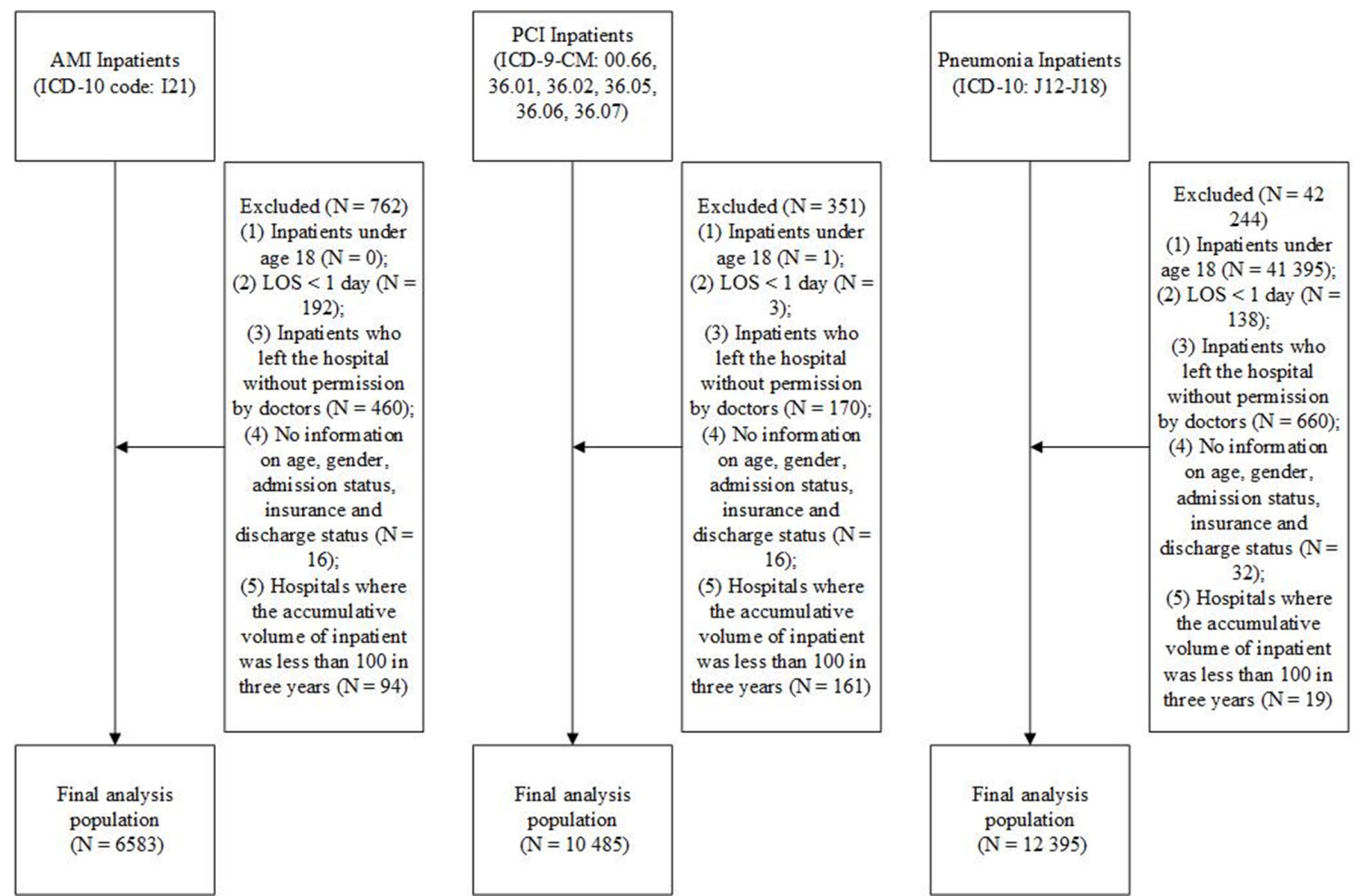

Figure 1 Flow diagram of patient selection. AMI, acute myocardial infarction; ICD-9, International Classification of Disease, Ninth Revision; ICD-10, ICD, Tenth Revision; LOS, length of stay; PCI, percutaneous coronary intervention.

\section{Study population}

A total of 13 tertiary-level public hospitals in Shenzhen were used as sample in this study. Using patients' primary diagnosis and procedures codes, we identified 7345 patients with AMI (ICD-10 code: I21), 54639 patients with pneumonia (ICD-10: J12-J18) and 10836 patients who had PCI (ICD-9-CM: 00.66, 36.01, 36.02, 36.05, 36.06, 36.07) in Shenzhen from 1 January 2015 to 31 December 2017. As shown in figure 1, we excluded hospitals with less than 100 cumulative hospital admissions in 3 years, because we studied the relationship between volume and outcome, that is, hospitals with large volume had better outcomes than hospitals with small volume, ${ }^{34}$ which means that the relationship between reimbursement rates and LOS may have been distorted. Additionally, the patients under 18 years, or whose information about age, gender, admission status, insurance and discharge status was not available, who were discharged within 1 day after admission and who left the hospital without permission by doctors were also excluded.

\section{Study variables}

In this study, independent variable of interest was reimbursement rate of inpatients, which was the actual reimbursement rate rather than policy one, and it was defined as one minus the ratio of OOP to the total expenditure, multiplied by $100 \%$, because the policy reimbursement rate and actual reimbursement rate of many outpatients is equal while the relationship may not be established for inpatients. The outcome of interest was LOS, which was defined as the number of consecutive hospital admission days during the stay for the definite treatment. LOS is a primary predictor of resource use. ${ }^{41}$

To study the effect of reimbursement rates on LOS, we controlled both patient-level and hospital-level characteristics known to be associated with LOS. Seven patient-level covariates (sex, age, marital status, admissions pathways, patient conditions for admission, Elixhauser Index and inpatient mortality) were included in our analysis. The patient condition for admission, which was set as a proxy of the severity of the disease, ${ }^{42}$ was evaluated by doctors. The admissions pathway was a noteworthy risk factor because emergency cases were expected to worsen in-hospital outcomes than outpatients' cases. The Elixhauser Index was used for comorbidity adjustment for administrative data. ${ }^{43}$ These three variables were used to correct the bias caused by different patient conditions. Considering possible survivor-treatment selection bias, ${ }^{44}$ in-hospital survival was also considered as a control variable in the equation. To adjust the risk factors, most studies only focused on patient-level factors. The hospital-level structural features affecting patients' resource use were also considered in this study. Five hospital-level covariates were also included (the number of open beds, the number of physicians per 100 beds, the number of nurses per 100 beds, inpatient care per doctor and government financial aid).

\section{Statistical analysis}

We constructed multilevel negative binomial regression models to explore the association between reimbursement rates and LOS. Three regression models were constructed 
to assess the changes in the estimates accounting for different groups of potential confounding factors. There was only one variable in the first model, and it was reimbursement rates. The second model was used to control all patient-level and hospital-level characteristics. Besides, the deceased were often more susceptible to the impact of reimbursement rates and consumed more medical resources because they badly wished to survive. Therefore, an interaction term between reimbursement rates and in-hospital survival was added in the third model to assess whether the relationship between reimbursement rates and LOS differed by in-hospital survival. A negative binomial regression was appropriate due to the excessive dispersion of the LOS. The superiority of this model over the ordinary Poisson regression model was confirmed by the Vuong test and likelihood ratio test. In addition, a multilevel model was recommended while taking the clustering of data into account. ${ }^{45}$ The conditions of patients admitted to the same hospital were different and they obviously had their own choice on hospital. Therefore, patient conditions for admission in the same hospital tended to be generally more serious. In terms of data hierarchy, a two-level model was constructed to group patients' outcomes within hospitals, in which sampled patients (first level) were nested into six or seven hospitals (second level).

The incidence rate ratio (IRR), 95\% CI and marginal effect were reported, among which the marginal effect needs to be specifically explained as it indicated the instantaneous rate of change when reimbursement rates changed when other covariates were assumed to be constant. Though IRRs were recommended to be reported, they could be misleading because it did not indicate an obvious or consistent effect on the predicted probabilities. ${ }^{46}$ Marginal effect is a way of presenting the difference of results in probability, which is more informative than IRRs and relative risks especially when there are interactions in our model. ${ }^{47}$ The average marginal effects (AME) were used to evaluate the marginal effect. The clean and data visualisations of all data were processed in $\mathrm{R}$ Studio (V.3.5.0) while statistical analyses were performed in Stata V.15.0. The statistical significance was defined as a p value of 0.05 , and all tests were two-sided.

\section{Patient and public involvement}

We report no patient or public involvement in the design or implementation of the study.

\section{RESULTS}

The statistics of health outcomes, demographic characteristics, comorbid conditions, and hospital characteristics for patients hospitalised with AMI, pneumonia and PCI are summarised in table 1. A total of 6583 inpatients with AMI, 12395 inpatients with pneumonia and 10485 in patients who had PCI as their principal diagnoses were analysed. The in-hospital mortality was $4.60 \%, 2.36 \%$ and $1.03 \%$, respectively. The median LOS of patients was 8 days $(\mathrm{IQR}=6.0)$ for $\mathrm{AMI}, 8$ days $(\mathrm{IQR}=4.0)$ for pneumonia and 7 days $(\mathrm{IQR}=6.0)$ for PCI.

The associated $\chi 2$ value $(\chi 2=397.00$, Prob $\geq \chi 2=0.000$; $\chi 2=115.68$, Prob $\geq \chi 2=0.000 ; \chi 2=1587.43$, Prob $\geq \chi 2=0.000$ ) of the fitted multivariate model strongly suggests that $\alpha$ is non-zero and the negative binomial model is more appropriate than the Poisson model. The selected IRRs and marginal effect from three multilevel negative binomial regression models for inpatients with AMI, pneumonia and PCI surgery are shown in table 2 (the details of the models are illustrated in online supplemental appendix). Model 1 showed the estimated results with 'reimbursement rate' as the sole independent variable and the count of LOS as the dependent variable. The AME for reimbursement rate specifies that, for each additional unit of reimbursement rate, there are averages of $0.011(95 \%$ CI, 0.008 to $0.015 ; \mathrm{p}<0.001)$ and 0.008 (95\% CI, 0.006 to 0.011; $\mathrm{p}<0.001)$ additional LOS for AMI and PCI, respectively. The AME for reimbursement rate specifies that, for each additional unit of reimbursement rate, there is not additional LOS (95\% CI, -0.003 to $0.002 ; \mathrm{p}=0.881$ ) for inpatients with pneumonia.

The AME for reimbursement rate in model 2 indicated that there was an average of 0.019 additional LOS (95\% CI, 0.015 to 0.023 ; $\mathrm{p}<0.001$ ) for each additional unit of reimbursement rate. For inpatients with pneumonia, the AME for the reimbursement rate suggested that there was an average of 0.011 additional LOS (95\% CI, 0.009 to $0.014 ; \mathrm{p}<0.001)$ for each additional unit of reimbursement rate. For inpatients who had PCI surgery, the AME for the reimbursement rate indicated that there was an average of 0.013 additional LOS (95\% CI, 0.010 to 0.016 ; $\mathrm{p}<0.001)$ for each additional unit of reimbursement rate.

In model 3 where there was an interaction between the reimbursement rate and in-hospital survival, each additional reimbursement rate was averagely associated with a 0.017 increase $(95 \% \mathrm{CI}, 0.013$ to $0.021 ; \mathrm{p}<0.001)$ in the predicted probability of hospitalisation for the living patients with AMI and a similar 0.044 increase $(95 \%$ CI, 0.031 to $0.058 ; \mathrm{p}<0.001)$ for the deceased patients with AMI. Each additional reimbursement rate was associated with a 0.012 increase $(95 \% \mathrm{CI}, 0.009$ to $0.014 ; \mathrm{p}<0.001)$ in the predicted probability of hospitalisation for the living inpatients with pneumonia and a similar 0.002 increase (95\% CI, -0.013 to 0.016 ; $\mathrm{p}=0.818$ ) for the deceased inpatients with pneumonia. For patients hospitalised with PCI surgery, each additional reimbursement rate was associated with a 0.013 increase $(95 \%$ CI, 0.010 to 0.016 ; $\mathrm{p}<0.001)$ in the predicted probability of hospitalisation for the living inpatients and a similar 0.034 increase $(95 \% \mathrm{CI}$, 0.017 to $0.051 ; \mathrm{p}<0.001)$ for the deceased inpatients.

\section{DISCUSSION}

The standardised administrative EHRs and multilevel negative binomial regression models were used to explore the association between the reimbursement rate and LOS among inpatients admitted for AMI, pneumonia and PCI 
Table 1 Patient and hospital-level characteristics and patient outcomes classified by the type of disease

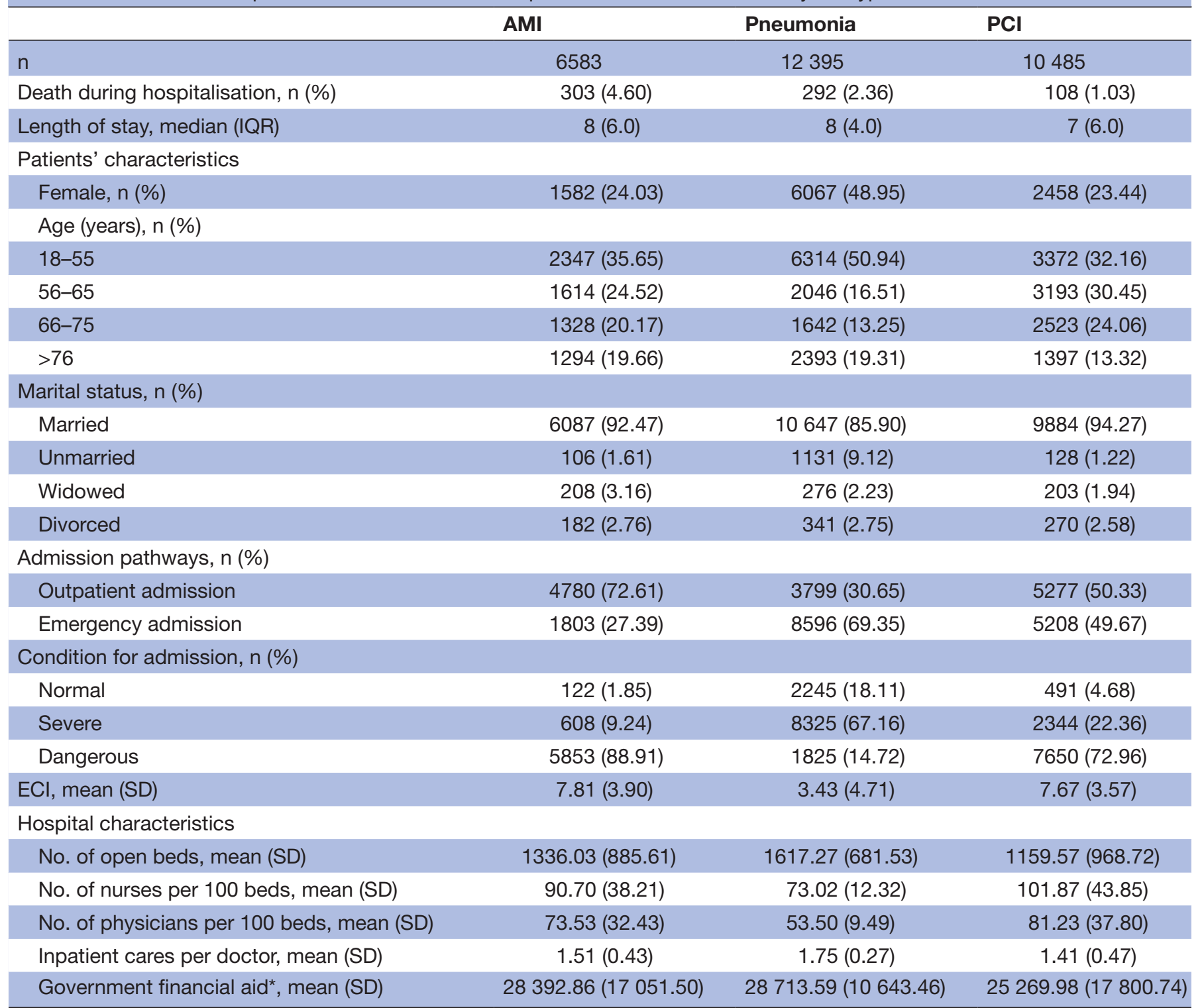

* $¥ 1=\$ 0.145$.

AMI, acute myocardial infarction; ECI, Elixhauser Comorbidity Index; PCl, percutaneous coronary intervention.

surgery in this study. It was found that a higher reimbursement rate resulted in a longer LOS after all patient-level and hospital-level confounding variables were adjusted. However, differences might not be statistically significant after an interaction term between the reimbursement rate and in-hospital survival was added, which depended on patients' category of disease or surgery. Our study is a supplementary to the existing literature in evaluating the correlation between health insurance generosity and utilisation in LMICs. The policymakers and hospital administrators are advised to be aware of the increase in LOS caused by increased reimbursement rates, which may be partially driven by the moral hazard during hospitalisation.

Most obviously, a higher reimbursement rate resulted in a longer LOS even after measurable patient-level and hospital-level confounding factors were adjusted. To our knowledge, the association between the reimbursement rate and LOS across different diagnoses or surgeries was rarely studied. Based on existing literature, LOS differs by insurance status. For example, the evidence for longer mean LOS among Medicaid patients than commercial or Medicare was detected by using Market Sean administrative claims data. ${ }^{41}$ NCMS patients had significantly shorter LOS than UEBMI patients, which was attributed to the strong association between reimbursement rates and insurance status. ${ }^{48}$ In terms of benefit packages and financial protection, UEBMI was viewed as a higher-level reimbursement rate than NCMS and URBMI. ${ }^{49}$ Nevertheless, additional uncertainty arose from the integration of urban and rural residents' basic medical insurance schemes for equitable access to inpatient care for people 
Table 2 Multilevel negative binomial regression analysis of relationship between reimbursement rates and LOS

\begin{tabular}{|c|c|c|c|}
\hline & LOS & & \\
\hline Reimbursement rate & AMI & Pneumonia & $\mathrm{PCl}$ \\
\hline \multicolumn{4}{|l|}{ Model 1 (unadjusted) } \\
\hline Marginal effect (95\% Cl) & $0.011(0.008 \text { to } 0.015)^{\star \star *}$ & $-0.000(-0.003$ to 0.002$)$ & $0.008(0.006 \text { to } 0.011)^{\star * *}$ \\
\hline \multicolumn{4}{|c|}{ Model 2 (risk adjusted for patient characteristics and hospital characteristics) } \\
\hline Marginal effect $(95 \% \mathrm{Cl})$ & $0.019(0.015 \text { to } 0.023)^{\star \star \star}$ & $0.011(0.009 \text { to } 0.014)^{\star \star \star}$ & $0.013(0.010 \text { to } 0.016)^{\star \star \star}$ \\
\hline \multicolumn{4}{|c|}{ Model 3 (model 2+reimbursement rate*in-hospital death interaction) } \\
\hline IRR (95\% Cl) & $1.002(1.001 \text { to } 1.002)^{\star \star \star}$ & $1.001(1.001 \text { to } 1.002)^{\star \star \star}$ & $1.002(1.001 \text { to } 1.002)^{\star \star \star}$ \\
\hline \multirow[t]{2}{*}{ Marginal effect $(95 \% \mathrm{Cl})$} & $0.017(0.013 \text { to } 0.021)^{\star \star *}$ & $0.012(0.009 \text { to } 0.014)^{\star \star *}$ & $0.013(0.010 \text { to } 0.016)^{\star \star \star}$ \\
\hline & $0.044(0.031 \text { to } 0.058)^{\star \star \star}$ & $0.002(-0.013$ to 0.016$)$ & $0.034(0.017 \text { to } 0.051)^{\star \star *}$ \\
\hline
\end{tabular}

All models are only reporting the IRR value and marginal effect of reimbursement rate. The IRR values of the confounding variables are shown in the online supplemental appendix.

${ }^{* * *} \mathrm{P}<0.001$.

AMI, acute myocardial infarction; IRR, incidence rate ratio; LOS, length of stay; PCI, percutaneous coronary intervention.

covered by different health insurance schemes since $2016 .^{37} 50$ Moreover, the actual reimbursement rates of certain medical insurance varied dramatically across county level or municipal level, which mainly depended on the reimbursement drug list, diagnosis and treatment project, and medical service facility list. ${ }^{30} 37$ Hence, to some extent, finding out the association between the actual reimbursement rates and LOS is of great significance to SHI reform.

The association between reimbursement rates and LOS could be possibly explained by the fact that a higher reimbursement rate had a positive effect on the utilisation of health services by inpatients. Patients can seek more comprehensive and more high-quality health services in the hospitals. ${ }^{51} 52$ There are, however, other more convincing explanations. It is believed that positive results are due to the overuse of expensive services and excessive treatment. ${ }^{30} 53$ For one thing, the reimbursement rate of inpatient services is usually higher than outpatient services, which is why patients are willing to be hospitalised instead of being treated as outpatients. Furthermore, a higher reimbursement rate probably perversely encourages doctors for overdiagnosis and overtreatment, thus prolonging LOS. Taking patients with pneumonia as an example, the AME for the reimbursement rate indicated that for each additional unit of cost-sharing, there was an average of 0.011 additional LOS (95\% CI, 0.008 to 0.015 ; $\mathrm{p}<0.001$ ). Though $81.2 \%$ of patients with communityacquired pneumonia were low-risk patients and clinical stability on admission accounted for $21.7 \%$ of patients, the median LOS was 5.0 days after achieving clinical stability in China according to the previous research. ${ }^{54}$ There is surely a point worth further discussion. Inpatients may have to undergo further treatment or rehabilitation in high-level hospitals in all BRICS where the population is unevenly distributed with exceptionally large rural areas remote to most specialty hospitals and university clinics. ${ }^{2}$ And efforts to bolster primary healthcare in LMICs are also limited.$^{55}$ The weak medical service capacity in primary healthcare facilities affects patients' choice of healthcare providers. ${ }^{33557}$ This is precisely why inpatients are reluctant to leave high-quality hospitals because of their lack of trust in primary care providers. Taken together, these results indicate that moral hazard may occur in situations where health insurance coverage is widespread, healthcare providers may overprovide healthcare services, and healthcare users may overuse healthcare services.

Interestingly, it was found that the association between reimbursement rates and LOS depended on patients' disease or surgery category after the interaction term was added between reimbursement rates and in-hospital survival and that the AME of the reimbursement rate among deceased patients was greater than that among recovering patients with AMI and PCI surgery discharged from the hospitals. These findings reflected that a higher reimbursement rate for deceased inpatients could better motivate them to use medical services. The conditions of the deceased inpatients were usually more complicated so they needed to consume more medical resources. Therefore, they might be more sensitive to the changes in reimbursement rates, meaning that their LOS might be longer than survived inpatients as reimbursement rates increased. The reimbursement rate should be a certain tilt for such patients to avoid catastrophic health expenditure. Conversely, we found that each additional reimbursement rate was associated with a 0.002 increase $(95 \% \mathrm{CI}$, -0.013 to $0.016 ; \mathrm{p}=0.818$ ) for inpatients who died of pneumonia. Consequently, there was no evidence that a higher reimbursement rate prolonged LOS. It was also possibly because that subsidising inpatient cost through medical insurance schemes was at a high level. The average LOS of the survivor was 9.3 days, while that of the deceased 
was 17.9 days and was 1.9 times of the former. Additionally, Shenzhen is one of only four first-tier cities in China. Premiums based on the level of the enrollee's salary and the employer's cost-sharing are sufficient, and insurance programmes are heavily subsidised by the government. There are extensive benefit packages including drug list, diagnosis and treatment project, and medical service facility list. In 2017, the fund income of UEBMI was $¥ 28.925$ billion and that of URBMI was ¥2.714 billion, of which the financial subsidies at all levels were $¥ 1.081$ billion. ${ }^{58}$ Under such circumstance, there was no point in improving reimbursement rates because excessive protection violates the principles of basic medical insurance. To sum up, disease may play an important role in this relationship between reimbursement rate and LOS. For some diseases, the utilisation of inpatient service is more susceptible to changes in reimbursement rates, but not in others. This is principally associated with disease severity and the prices of medical treatments. According to Zaresani and Schmidt, ${ }^{20}$ more generous health insurance increases the incidence of expensive medical costs, such as vitro fertilisation treatment.

Investigating the relationship between reimbursement rate and LOS would shed further light on this underappreciated health financing sustainability challenge, which is attributed to moral hazard in LMICs. The findings of this study have several important implications for future practice. On the one hand, it is critical to dynamically supervise the flow of health insurance funds to prevent medical resources from being wasted. Providers are also advised to accurately and timely identify abnormal hospitalised cases and treatment behaviours. According to the feedback on different diseases or surgeries and essential economic assessment, providers are supposed to adjust reimbursement rates such as increasing the reimbursement rate for dual antiplatelet therapy needed by AMI. ${ }^{59}$ The dynamic supervision has been placed in a remarkably important position since the National Medical Insurance Administration was established. On the other hand, as mentioned above, the weak service capacity of primary healthcare institutions leads to excessive utilisation of inpatient services. Both domestic policies and international trends indicate that the future public hospitals in China are likely to be county-level hospitals. ${ }^{60}$ Therefore, it is quite essential to improve the service capabilities of primary healthcare providers. The policy suggestions include establishing performance-based incentives for primary healthcare providers, setting reasonable drug price, and providing career development opportunities for primary healthcare professionals. ${ }^{30335761}$

This study has certain limitations. First, it remains unclear whether patients' prolonged LOS can be defined 'reasonable' and to what extent it can be considered 'appropriate' (ie, under different reimbursement rates). Further research is recommended in these areas. Second, there are potential data defects in the present study. The data were mainly from the electronic medical records of hospitals, so there were limited variables. We were unable to identify the underlying causal mechanism because there were no data about the process of treatment. Clinical laboratory data may affect LOS. ${ }^{62}$ However, we adjusted all collected patient-level and hospital-level confounders, thus making it feasible by using administrative data in risk adjustment. ${ }^{63}$ Last, these results have certain limitation. The economic level and health investment are higher in Shenzhen than those in other cities. It is likely that the reimbursement rates may exert enormous influence on LOS in other cities if the local government increases health investment to reduce health disparities.

\section{CONCLUSIONS}

The purpose of this study was to explore the relationship between reimbursement rates and LOS. The findings suggest that increased reimbursement rates lead to increased losses for different types of disease or surgeries. These findings provide a mixed story concerning the reform of effective reimbursement rate for stakeholders including policymakers and hospital administrators. Increasing reimbursement rate can better promote the utilisation of healthcare services, but it may also bring unnecessary waste of healthcare resources, namely moral hazard, which needs to be paid attention to by stakeholders. Although this study does not prove the underlying mechanism of the effect of effective reimbursement rate on LOS, it partially points out the direction of health insurance management. Policymakers and hospital administrators are advised to reduce moral hazard by performing dynamic supervision and improving the service capabilities of primary healthcare providers.

Acknowledgements The authors sincerely thank the Public Hospital Management Center in Shenzhen for providing us with the data used in this study.

Contributors JN, JY and HT conceived the study idea and interpreted the data. $\mathrm{JN}, \mathrm{LL}$ and EC drafted and revised the article. YP and HX undertook the statistical analysis. JY was the principal investigator of the project. All authors have approved the final version of the manuscript for publication. The authors disclosed the receipt of the following financial support for the research, authorship and/or publication of this article.

Funding This work was supported by the National Natural Science Foundation of China (Grant Number: 71774061).

Competing interests None declared.

Patient consent for publication Not required.

Ethics approval Confidential information including name, ID card number residential address, postal code and insurance number were excluded from the database. Huazhong University of Science and Technology, which was not directly engaged with the data collection, exempted the study as human subject research for secondary analysis of data as defined by DHHS regulations 45 CFR 46.102.

Provenance and peer review Not commissioned; externally peer reviewed.

Data availability statement Data are available upon reasonable request from the Public Hospital Management Center in Shenzhen.

Supplemental material This content has been supplied by the author(s). It has not been vetted by BMJ Publishing Group Limited (BMJ) and may not have been peer-reviewed. Any opinions or recommendations discussed are solely those of the author(s) and are not endorsed by BMJ. BMJ disclaims all liability and responsibility arising from any reliance placed on the content. Where the content includes any translated material, BMJ does not warrant the accuracy and reliability of the translations (including but not limited to local regulations, clinical guidelines, 
terminology, drug names and drug dosages), and is not responsible for any error and/or omissions arising from translation and adaptation or otherwise.

Open access This is an open access article distributed in accordance with the Creative Commons Attribution Non Commercial (CC BY-NC 4.0) license, which permits others to distribute, remix, adapt, build upon this work non-commercially, and license their derivative works on different terms, provided the original work is properly cited, appropriate credit is given, any changes made indicated, and the use is non-commercial. See: http://creativecommons.org/licenses/by-nc/4.0/.

ORCID iD

Jingkai Yue http://orcid.org/0000-0003-3614-9619

\section{REFERENCES}

1 Jakovljevic M, Jakab M, Gerdtham U, et al. Comparative financing analysis and political economy of noncommunicable diseases. J Med Econ 2019;22:722-7.

2 Jakovljevic MB. BRIC's growing share of global health spending and their diverging pathways. Front Public Health 2015;3:135.

3 Jakovljevic MM. Comparison of historical medical spending patterns among the BRICS and G7. J Med Econ 2016;19:70-6.

4 Jakovljevic M, Potapchik E, Popovich L, et al. Evolving health expenditure landscape of the BRICS nations and projections to 2025. Health Econ 2017;26:844-52.

5 Rancic N, Jakovljevic MM. Long term health spending alongside population aging in $\mathrm{N}-11$ emerging nations. East Eur Bus Econ J 2016;2:2-26.

6 Jakovljevic M, Getzen TE. Growth of global health spending share in low and middle income countries. Front Pharmacol 2016;7:21.

7 Jakovljevic MB. The key role of the leading emerging bric markets in the future of global health care. Serbian $J$ of Exp \& Clin Res 2014;15:139-43.

8 Marten R, Mclntyre D, Travassos C, et al. An assessment of progress towards universal health coverage in Brazil, Russia, India, China, and South Africa (BRICS). The Lancet 2014;384:2164-71.

9 WHO. World health report 2010. health systems financing. Path to universal coverage. Geneva: World Health Organization, 2010.

10 Dusetzina SB, Winn AN, Abel GA, et al. Cost sharing and adherence to tyrosine kinase inhibitors for patients with chronic myeloid leukemia. J Clin Oncol 2014;32:306-11.

11 Guo N, Iversen T, Lu M, et al. Does the new cooperative medical scheme reduce inequality in catastrophic health expenditure in rural China? BMC Health Serv Res 2016;16:653.

12 González López-Valcárcel B, Librero J, García-Sempere A, et al. Effect of cost sharing on adherence to evidence-based medications in patients with acute coronary syndrome. Heart 2017;103:1082-8.

13 Xiang L, Pan Y, Hou S, et al. The impact of the new cooperative medical scheme on financial burden of tuberculosis patients: evidence from six counties in China. Infect Dis Poverty 2016;5:8.

14 Miao Y, Gu J, Zhang L, et al. Improving the performance of social health insurance system through increasing outpatient expenditure reimbursement ratio: a quasi-experimental evaluation study from rural China. Int J Equity Health 2018;17:89.

15 Finkelstein AN, Taubman SL, Allen HL, et al. Effect of Medicaid coverage on ED use - further evidence from Oregon's xxperiment. $N$ Engl J Med 2016;375:1505-7.

16 Taubman SL, Allen HL, Wright BJ, et al. Medicaid increases emergency-department use: evidence from Oregon's health insurance experiment. Science 2014;343:263-8.

17 Einav L, Finkelstein A. Moral hazard in health insurance: what we know and how we know it. J Eur Econ Assoc 2018;16:957-82.

18 Finkelstein A, Taubman S, Wright B, et al. The Oregon health insurance experiment: evidence from the first year. $Q \mathrm{~J}$ Econ 2012;127:1057-106.

19 Pauly MV. The economics of moral hazard: Comment. The american economic review 1968;58:531-7.

20 Zaresani A, Schmidt L. Generosity of health insurance coverage: intensive and extensive margin effects on utilization, 2020.

21 Nyman JA. Is 'moral hazard' inefficient? The policy implications of a new theory. Health Aff 2004;23:194-9.

22 Zhou ZZL, Zhou Z, Li Z, et al. The effects of China's urban basic medical insurance schemes on the equity of health service utilisation: evidence from Shaanxi Province. Int J Equity Health 2014.

$23 \mathrm{Kim} \mathrm{M}$, Kwon S. The effect of outpatient cost sharing on health care utilization of the elderly. J Prev Med Public Health 2010;43:496-504.

24 Chandra A, Gruber J, McKnight R. The impact of patient costsharing on low-income populations: evidence from Massachusetts. $J$ Health Econ 2014;33:57-66.
25 Yip W, Eggleston K. Addressing government and market failures with payment incentives: Hospital reimbursement reform in Hainan, China. Soc Sci Med 2004;58:267-77.

26 Tambor M, Pavlova M, Golinowska S, et al. Can European countries improve sustainability of health care financing through patient CostSharing? Front Public Health 2015;3:196.

27 Jakovljevic M, Timofeyev Y, Ekkert NV, et al. The impact of health expenditures on public health in BRICS nations. J Sport Health Sci 2019;8:516-9.

28 The role of AIIB and NDB in the development of the Asian finance. 2019 International Conference on contemporary education and society development (ICCESD 2019. Atlantis Press, 2019.

29 Jakovljevic MB, Milovanovic O. Growing burden of noncommunicable diseases in the emerging health markets: the case of BRICS. Front Public Health 2015;3:65.

30 Liu GG, Vortherms SA, Hong X. China's health reform update. Annu Rev Public Health 2017;38:431-48.

31 Zhang C, Lei X, Strauss J, et al. Health insurance and health care among the mid-aged and older Chinese: evidence from the National baseline survey of CHARLS. Health Econ 2017;26:431-49.

32 Shen M, He W, Yeoh E-K, et al. The association between an increased reimbursement cap for chronic disease coverage and healthcare utilization in China: an interrupted time series study. Health Policy Plan 2020;35:1029-38.

33 Fang $\mathrm{H}$, Eggleston $\mathrm{K}$, Hanson $\mathrm{K}$, et al. Enhancing financial protection under China's social health insurance to achieve universal health coverage. BMJ 2019;365:I2378.

34 Word Bank. The long March to universal coverage: lessons from China, 2013. Available: https://openknowledge.worldbank.org/ bitstream/handle/10986/13303/74960.pdf [Accessed 3 January, 2020].

35 Fu W, Zhao S, Zhang Y, et al. Research in health policy making in China: out-of-pocket payments in healthy China 2030. BMJ 2018;360:k234.

36 AJ H, Meng Q. The Chinese National health care reform: on the mend? Routledge, 2017

37 Meng Q, Fang $\mathrm{H}$, Liu X, et al. Consolidating the social health insurance schemes in China: towards an equitable and efficient health system. Lancet 2015;386:1484-92.

38 Shan L, Zhao M, Ning N, et al. Dissatisfaction with current integration reforms of health insurance schemes in China: are they a success and what matters? Health Policy Plan 2018;33:345-54.

$39 \mathrm{Li} \mathrm{X}$, Zhang W. The impacts of health insurance on health care utilization among the older people in China. Soc Sci Med 2013;85:59-65.

40 National Health and Family Planning Commission. The quality management and control indicators of hospitalized patient records by Ministry of health, 2016. Available: http://www.nhc.gov.cn/ yzygj/s2909/201606/26807a94a41d4550970317da7729218c.shtml [Accessed 3 January, 2020].

41 Allen LA, Smoyer Tomic KE, Wilson KL, et al. The inpatient experience and predictors of length of stay for patients hospitalized with systolic heart failure: comparison by commercial, Medicaid, and Medicare payer type. J Med Econ 2013;16:43-54.

$42 \mathrm{Xu} \mathrm{Y,} \mathrm{Liu} \mathrm{Y,} \mathrm{Shu} \mathrm{T,} \mathrm{et} \mathrm{al.} \mathrm{Variations} \mathrm{in} \mathrm{the} \mathrm{quality} \mathrm{of} \mathrm{care} \mathrm{at} \mathrm{large} \mathrm{public}$ hospitals in Beijing, China: a Condition-Based outcome approach. PLoS One 2015;10:e0138948.

43 Elixhauser A, Steiner C, Harris DR, et al. Comorbidity measures for use with administrative data. Med Care 1998;36:8-27.

44 Cohen D, Manuel DG, Tugwell P, et al. Does higher spending improve survival outcomes for myocardial infarction? examining the CostOutcomes relationship using time-varying covariates. Health Serv Res 2015;50:1589-605.

45 Rivard S, Lapointe L. A multilevel model of resistance to information technology implementation. MIS Quarterly 2005;29:461.

46 Mize T. Best practices for estimating, interpreting, and presenting nonlinear interaction effects. Sociol Sci 2019;6:81-117.

$47 \mathrm{Ai} \mathrm{C}$, Norton EC. Interaction terms in logit and probit models. Econ Lett 2003;80:123-9.

48 Lin X, Cai M, Tao H, et al. Insurance status, inhospital mortality and length of stay in hospitalised patients in Shanxi, China: a crosssectional study. BMJ Open 2017;7:e015884.

49 Su S, Bao H, Wang X, et al. The quality of invasive breast cancer care for low reimbursement rate patients: a retrospective study. PLoS One 2017;12:e0184866

50 Zhu K, Zhang L, Yuan S, et al. Health financing and integration of urban and rural residents' basic medical insurance systems in China. Int J Equity Health 2017;16:194.

51 Zhou Z, Zhou Z, Gao J, et al. The effect of urban basic medical insurance on health service utilisation in Shaanxi Province, China: a comparison of two schemes. PLoS One 2014;9:e94909. 
52 You X, Kobayashi Y. The new cooperative medical scheme in China. Health Policy 2009;91:1-9.

53 Morgan DJ, Dhruva SS, Wright SM, et al. Update on medical practices that should be questioned in 2015. JAMA Intern Med 2015;175:1960-4.

54 Chen L, Zhou F, Li H, et al. Disease characteristics and management of hospitalised adolescents and adults with community-acquired pneumonia in China: a retrospective multicentre survey. BMJ Open 2018;8:e018709.

55 Kremer M, Glennerster R. Improving health in developing countries, 2011: 201-315.

56 Audibert M, Mathonnat J, Pelissier A, et al. Health insurance reform and efficiency of township hospitals in rural China: an analysis from survey data. China Economic Review 2013;27:326-38.

57 Meng Q, Mills A, Wang L, et al. What can we learn from China's health system reform? BMJ 2019;365:12349.

58 Bureau of Social Insurance Fund Administration S. Shenzhen social insurance information disclosure notice 2017. Available: http://szsi.
Sz.gov.cn/sbjxxgk/tjsj/sicbltj/201804/t20180428_11803730.htm [Accessed 3 June, 2019].

59 Liu B, Yan H, Guo R, et al. The basic social medical insurance is associated with clinical outcomes in the patients with ST-elevation myocardial infarction: a retrospective study from Shanghai, China. Int J Med Sci 2014;11:905-17.

60 Barber SL, Borowitz M, Bekedam H, et al. The hospital of the future in China: China's reform of public hospitals and trends from industrialized countries. Health Policy Plan 2014;29:367-78.

61 Chen Y, Schweitzer SO. Issues in drug pricing, reimbursement, and access in China with references to other Asia-Pacific region. Value Health 2008;11 Suppl 1:S124-9.

62 Menéndez R, Cremades MJ, Martínez-Moragón E, et al. Duration of length of stay in pneumonia: influence of clinical factors and hospital type. Eur Respir J 2003;22:643-8.

63 Evans E, Imanaka Y, Sekimoto M, et al. Risk adjusted resource utilization for AMI patients treated in Japanese hospitals. Health Econ 2007;16:347-59. 